ORIGINAL PROF-2260

\title{
VAGINAL BIRTH AFTER CAESAREAN SECTION;
} FACTORS PREDICTING SUCCESS

\begin{abstract}
Dr. Sana Zahiruddin, Dr. Sumera Rauf Qureshi, Dr. Umer Farooq
ABSTRACT... Background: Cesarean section is the commonest obstetrical procedure, associated with increase in maternal morbidity, the cesarean section rate is steadily on the rise in our country which can give rise to a number of complications. Objective: To determine the factors associated with successful vaginal delivery after previous cesarean section. Study Design: Cross sectional study. Period: May 2009 to October 2009. Setting: Liaquat university hospital, Hyderabad. Material and Methods: a total of 96 women which fulfilled the selection criteria were included in the study. Results: The women included in the study had a mean age of + SD(range), $29.94+4.41$ successful vaginal birth was observed in $57(59.5 \%)$ women and 39(40.6\%) had an emergency repeat cesarean delivery. The factors favoring successful vaginal delivery were history of previous vaginal delivery and previous cesarean due to fetal distress or breech presentation, and patients having cesarean due to non progress of labor and no prior vaginal delivery were less likely to have a successful vaginal birth after having previous cesarean delivery. Conclusions: vaginal birth after caesarean section can be recommended in patients having prior vaginal delivery and previous caesarean due to fetal distress and breech presentation.
\end{abstract}

Key words: Cesarean Section, VBAC, Prior vaginal delivery.

Article Citation

Zahiruddin S, Qureshi SR, Farooq U. Vaginal birth after caesarean section: factors predicting success. Professional Med J 20(5): 759764.

\section{INTRODUCTION}

Caesarean section is the most common obstetrical procedure. Over the years Caesarean section rate is on the rise all over the world and this trend is closely being followed in our country ${ }^{1}$, although it is considered a relatively safe procedure but is still associated with increased maternal mortality and morbidity as compared to vaginal delivery?2.

The major issue with repeated caesarean deliveries is the increased chances of blood transfusion, hemorrhage, uterine rupture ${ }^{2}$ and placental complications ${ }^{3}$. This is more relevant in our part of the world where the family size is large and un availability of proper health care facilities make it a major health hazard with more and more women will present with previous scar will encounter these problems in subsequent pregnancies, also the cost of caring for these women will be substantially high affecting our already crippled economy.

Many interventions have been suggested to overcome this issue, such as decrease in the primary caesarean rate, offering trial of vaginal delivery after previous caesarean section to suitable women. Although there is no doubt that the trial of labor is relatively safe procedure, it is not risk free and should not be taken casually ${ }^{4}$. The greatest risk of adverse events is for the women who undergo trial of labor and end up in emergency caesarean section rather than a planned caesarean delivery ${ }^{5}$, necessitating the need for proper patient selection prior to attempting vaginal birth after caesarean section.

\section{PATIENTS AND METHODS}

This cross sectional study was conducted at Obstetrics and Gynecology unit-II, Liaquat university hospital, Hyderabad. From May 2009 to October 2009. A total of 96 women having previous one Caesarean delivery were included in the study having a term singleton pregnancy, clinically adequate pelvic dimensions and spontaneous onset of labor. Women having more than one prior Caesarean delivery, classical uterine incision , and severe medical and obstetrical complications(Diabetes, Hypertension, Multiple pregnancy, Intra uterine growth restriction, 
severe abruption ) were excluded from the study. Written informed consent was taken, detailed history, thorough clinical examination and relevant investigations were performed, patients were closely monitored for progress of labor, maternal and fetal condition and scar integrity, all the relevant information was recorded on a pre designed proforma.

Patient's age, parity, presence of previous vaginal delivery and indication of previous Caesarean section were taken as variables. Mean standard deviation was calculated for variables like age. Frequency and percentages were calculated for variables like previous vaginal delivery and success or failure of attempted vaginal birth after Caesarean section. Confounding variables were controlled by stratification by age and booking status of the patient.

\section{RESULTS}

Total 96 women were included in this study with mean age +/-SD(range), 29.94+/-4.41(20-40 years). Out of these women, successful vaginal birth after Caesarean section was observed in $57(59.4 \%)$ women and 39(40.6\%) women had an emergency Caesarean section.(Fig-1).

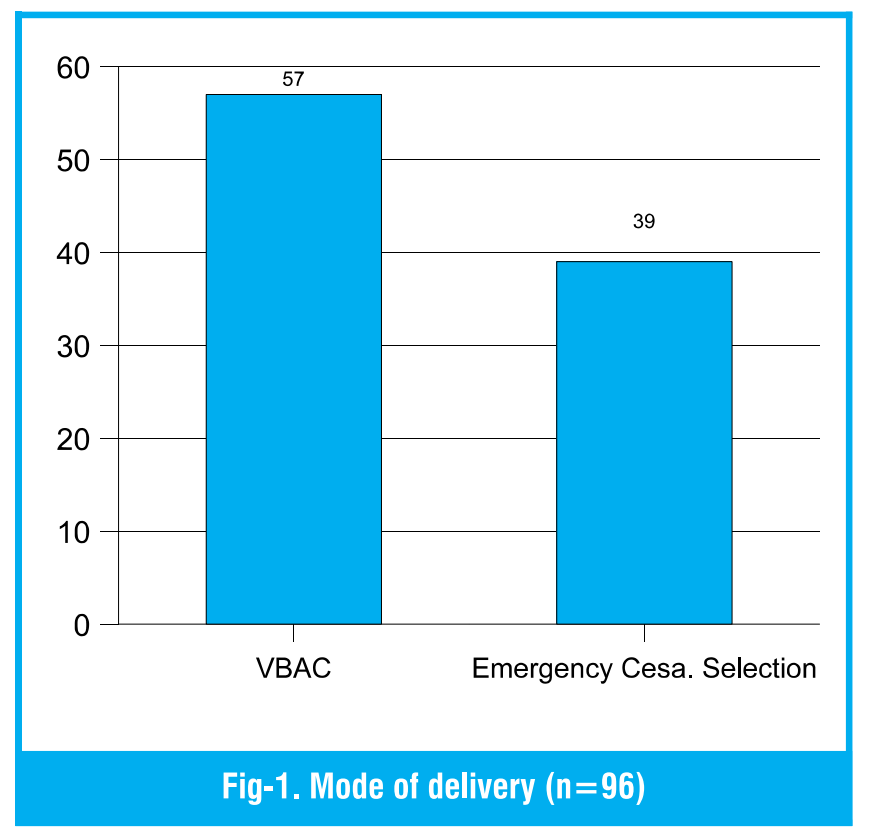

Out of 96 women, $59(61.45 \%)$ had previous vaginal delivery, out of them, $43(72.9 \%)$ had a successful vaginal birth after caesarean and $16(27.1 \%)$ had an emergency caesarean section.(Fig-2).

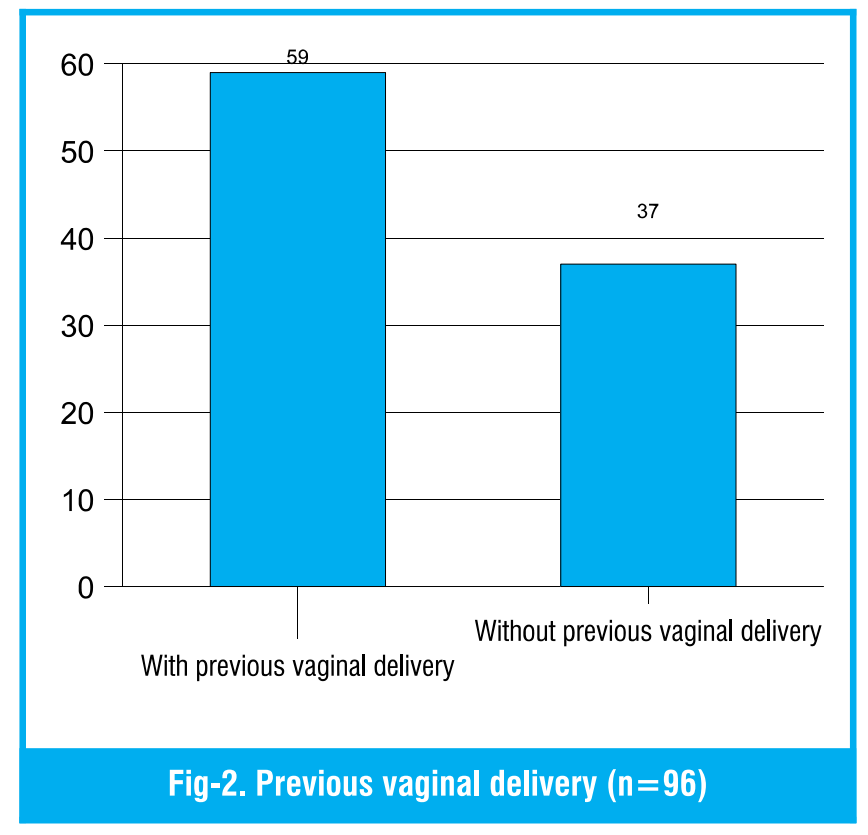

Among all women, indications of previous caesarean section, 30(31.3\%) women had a caesarean section due to non progress of labor, 21(21.9\%) fetal distress and breech presentation respectively, 13(13.5\%) Placenta praevia, 5(5.2\%) Transverse lie, 4(4.2\%) obstructed labor and 2(2.1\%) Cephalopelvic disproportion.(Table No.I).

\begin{tabular}{|l|c|}
\hline \multicolumn{2}{|l|}{ Indication of previous cesarean } \\
\hline Non progress of labour & $30(31.3 \%)$ \\
\hline Fetal distress & $21(21.9 \%)$ \\
\hline Breech presentation & $21(21.9 \%)$ \\
\hline Placenta praevia & $13(13.5 \%)$ \\
\hline Transverse Lie & $5(5.2 \%)$ \\
\hline Obstructed labour & $4(4.2 \%)$ \\
\hline Cephalo pelvic disproportion & $2(2.1 \%)$ \\
\hline
\end{tabular}

Table-I. Indication of previous cesarean section $(n=96)$ 
Indication of previous caesarean section, 30(31.3\%) women had a prior caesarean section due to non progress of labor, out of 57 patients, 11(19.3\%) delivered vaginally while out of 39 women $19(48.7 \%)$ were delivered by a repeat caesarean section.21(21.9\%) women had prior because of fetal distress. Out of 57 women $14(24.6 \%)$ delivered vaginally and $7(17.9 \%)$ women delivered by emergency caesarean section.( Table No.II).

\begin{tabular}{|c|c|c|c|}
\hline $\begin{array}{l}\text { Indication of } \\
\text { previous } \\
\text { cesarean } \\
\text { section }\end{array}$ & $\begin{array}{l}\text { VABC } \\
(n=57)\end{array}$ & $\begin{array}{c}\text { Emergency } \\
\text { caesarean } \\
(n=39)\end{array}$ & Total \\
\hline CPD & $1(1.8 \%)$ & $1(2.6 \%)$ & $2(2.1 \%)$ \\
\hline $\begin{array}{l}\text { Non progress } \\
\text { of labour }\end{array}$ & $11(19.3 \%)$ & 19 (48.7\%) & $30(31.3 \%)$ \\
\hline Fetal distress & $14(24.6 \%)$ & 7 (17.9\%) & $21(21.9 \%)$ \\
\hline $\begin{array}{l}\text { Breech } \\
\text { presentation }\end{array}$ & $16(28.1 \%)$ & $5(12.8 \%)$ & $21(21.9 \%)$ \\
\hline $\begin{array}{l}\text { Placenta } \\
\text { praevia }\end{array}$ & $9(15.8 \%)$ & $4(10.3 \%)$ & $13(13.5 \%)$ \\
\hline Transverse Lie & $4(7.0 \%)$ & $1(2.6 \%)$ & $5(5.2 \%)$ \\
\hline $\begin{array}{l}\text { Obstructed } \\
\text { labour }\end{array}$ & $2(3.5 \%)$ & $2(5.1 \%)$ & $4(4.2 \%)$ \\
\hline
\end{tabular}

Emergency caesarean section was performed in $39(40.62 \%)$ women, out of them, $23(24.0 \%)$ were because of non progress of labor, $6(6.3 \%)$ fetal distress and $10(10.4 \%)$ had caesarean section due to scar tenderness(Fig-3).

There was no case of uterine rupture, scar dehiscence in this study.

There were 5 (5.2\%) babies admitted in NICU for respiratory problems in women having a repeat emergency caesarean section, however there was no case of perinatal death in this study.

\begin{tabular}{|c|c|c|c|}
\hline & \multicolumn{2}{|c|}{ Vaginal delivery $(n=96)$} & \multirow[t]{2}{*}{ Total } \\
\hline & $\begin{array}{c}\text { With } \\
\text { previous } \\
(n=59)\end{array}$ & $\begin{array}{l}\text { Without } \\
\text { previous } \\
(n=37)\end{array}$ & \\
\hline \multicolumn{4}{|c|}{ Mode of delivery } \\
\hline VABC & $43(72.9 \%)$ & $14(37.8 \%)$ & $57(59.4 \%)$ \\
\hline $\begin{array}{l}\text { Emergency } \\
\text { Caesarean } \\
\text { Selection }\end{array}$ & $16(27.1 \%)$ & $23(62.2 \%)$ & $39(40.6 \%)$ \\
\hline
\end{tabular}

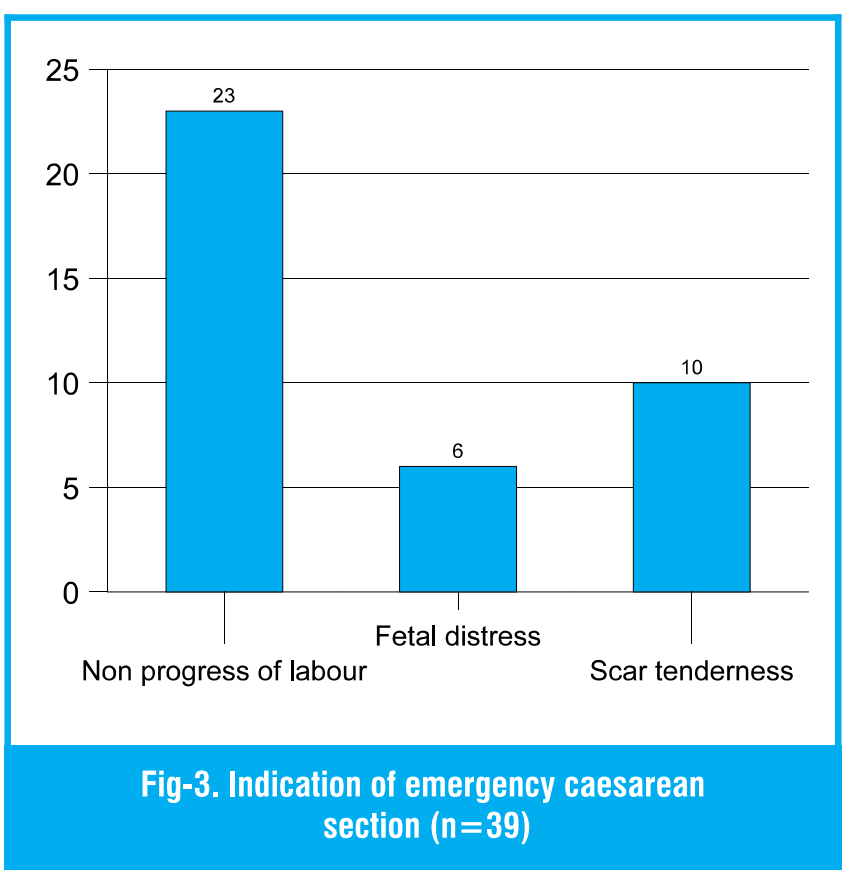

\section{DISCUSSION}

Vaginal birth after caesarean section has been considered an important step to lower the exceptionally high caesarean section rate all over the world. The Caesarean section rate in said unit during 2009 was $45 \%$ which is quite high, mainly because it is a tertiary care hospital receiving patients which are in critical condition often necessitating an operative delivery.

In this study 96 women having previous lower 
segment caesarean section were given trial of vaginal birth, the success rate of vaginal birth after caesarean section was $59.4 \%$, which was lower than the rates reported from studies conducted in Europe and US which were $75 \%{ }^{6}$ and $61.4 \%{ }^{7}$ respectively. The reported success rates study done in Karachi was $62 \%{ }^{8}$, however a recent study done in Nawabshah ${ }^{9}$ reported a success rate of $41.93 \%$ which is much lower than this study. As evident from highly variable success rates from above mentioned studies a key to success is proper patient selection.

There are few factors that have some influence on this matter and have the potential to predict the success of attempted vaginal birth after caesarean section.

Women having previous history of vaginal delivery have more chances of successful birth after caesarean section. In this study $59(61.45 \%)$ women had history of one vaginal delivery, among these women $72.9 \%$ delivered vaginally, this finding was consistent with a study done by Gyamfi et $\mathrm{al}^{10}$, this was also reported in a study done at Peshawar ${ }^{11}$. Although a study done by Hendler et al ${ }^{12}$ suggested prior vaginal delivery a risk factor for scar rupture/ dehiscence, this was not consistent with our study in which there was no case of scar separation in women having prior vaginal delivery.

Indications of previous Caesarean has some influence in the success of trial of labor.

In this study the indications were recorded from history and antenatal records, 30 patients had previous caesarean section due to non progress of labor out of which $19.3 \%$ had a successful vaginal birth and $48.7 \%$ had an emergency repeat caesarean delivery, this was in contrast when previous caesarean section was done due to fetal distress and breech presentation where vaginal birth was successful in $24.6 \%$ and $28.1 \%$ women and emergency caesarean delivery was done in $17 \%$ and $12 \%$ women respectively, these findings were consistent with findings of study done by Shipp et $\mathrm{al}^{13}$.

Many previous studies have pointed towards the influence of inter delivery interval ${ }^{14}$ and fetal birth weight $^{15}$ on the success of vaginal birth after caesarean section, however these factors were not associated with successful trial of labor in this study.

In this study 39 out of 96 women (40.6\%) had an emergency caesarean section; the major indications were non progress of labor, fetal distress and scar tenderness.

As reported in different studies, the risk of uterine rupture $^{16}$ is a known complication of trial of labor forcing obstetricians to choose an elective repeat caesarean section as a safer alternative, in this study there was no case of scar rupture/dehiscence.

There were 5 babies admitted in NICU, for respiratory problems, however there was no case of perinatal death, born to women included in this study, either delivered vaginally or by repeat caesarean section.

\section{CONCLUSIONS}

Offering trial of vaginal birth to women having previous caesarean delivery can play an important role in lowering the alarmingly increased caesarean section rate, patient selection is the key to a successful trial of labor.

Patients having a previous vaginal delivery have a higher chance of achieving a successful vaginal birth after caesarean and should be considered a strong candidate for it. Women having prior caesarean section due to failure to progress have more chances to have a repeat caesarean delivery, but women having previous caesarean due to fetal distress and breech presentation have a higher chances for achieving vaginal birth in subsequent pregnancy. 
There was no case of uterine rupture/scar dehiscence or perinatal mortality, in this study , therefore it can be considered a safe option in properly selected women. Copyright(C) 13 June, 2013.

\section{REFERENCES}

1. Smith GCS. Delivery after previous cesarean section. In: James DK, Steer PJ, Weiner CP, Gonic B, editor. High risk pregnancy management options. Philadelphia: Saunders; 2006.p1534-41.

2. Hassan A. Trial of scar and vaginal birth after caesarean section. J Ayub Med Coll 2005;17(1):5761.

3. Ashraf R, Bashir A, Gul A, Noor A, Chohan A. Frequency of Placenta Praevia with previous Cesarean section. ANNALS 2005 Jul-Sep;11(3):299300.

4. Flamm BL, Newman LA, Thomas SJ, Fallon D, Yoshida MM. Vaginal birth after Caesarean delivery: results of a 5-year multicenter collaborative study. Obstet Gynecol.1990;76:750-4.

5. Flamm BL, Goings JR, Liu Y, Wolde TKG. Elective repeat cesarean delivery versus trial of labor: a prospective multicenter study. Obstet Gynecol. 1994;83:927-32.

6. Adair CD, Sanchez R, Whitker D, Mecdyer DC, Farah L, Briones $D$. Trial of labor in patients with a previous lower uterine segment vertical cesarean section. Am J Obstet Gynecol 1996;174:966-70.

7. Landon MB, Hauth JC, Leveno KJ : Maternal and Perinatal outcomes associated with a trial of labor after priop cesarean delivery. $N$ Eng $J$ Med 2004;351:2581-9.

AUTHOR(S):

1. DR. SANA ZAHIRUDDIN MBBS, FCPS

Consultant Gynecologist Aga Khan Secondary Hospital, Hyderabad, Sindh.

2. DR. SUMERA RAUF QURESHI MBBS, FCPS

Gynae Unit-III

Liaqat University Hospital, Hyderabad, Sindh.
8. Macones GA, Hausman N, Edelstein R, et al: Predicting outcomes of trials of labor in women attempting vaginal birth after cesarean delivery: A comparison of multivariate methods with neural networks. Am J Obstet Gynecol 2001;184:409-13.

9. McDowell A, Engel A, Massey JT, Mavrer K. Plan and operation of the second National Health and Nutrition Examination Survey,1976-80. Hyattsville, MD: National centre for health statistics;1981:DHHS publication no. 81-1317.

10. Choudhary SM, Ayaz A. Effects to reduce Caesarean section rate. J Surg Pak 2003;8(1):25-7.

11. Nisa M, Hassan L. Trend of vaginal delivery after previous one Caesarean section in a tertiary care hospital. Pak J Med Res 2004;43(2):60-4.

12. Khero RB, Memon GN, Rubina A, Wagan F, Jillani K, Maqsood $S$. Vaginal birth after cesarean section. Med Channel 2007 Oct-Dec;14(4):66-8.

13. Clark SL, Elington GS, Beall M, Phelan JP. Effect of indication of previous cesarean section on subsequent delivery outcome in patients undergoing a trial of labor. J Reprod Med 1984;29:22-5.

14. Zelop CM, Shipp TD, Repke JT, Cohen A, Liebermann E. Outcomes of trial of labor following previous cesarean section delivery among women with fetuses weighing $\mathbf{7} \mathbf{4 0 0 0 g}$, Am J Obstet Gynecol 2001;185:903-5.

15. Society of Obstetricians and Gynaecologists of Canada. Vaginal birth after previous Cesarean section. Clinical practice Guideline no. 68. Ottawa(ON):SOGC; December 1997. 


\section{PREVIOUS RELATED STUDIES}

Sunbal Kashif, Malahat Mansoor, Rubina Tariq, Tayyaba Tahira. VAGINAL BIRTH AFTER CAESAREAN SECTION; TO EVALUATE FACTORS FOR SUCCESSFUL OUTCOME (Original) Prof Med Jour 17(4) 665-669 Oct, Nov, Dec 2010.

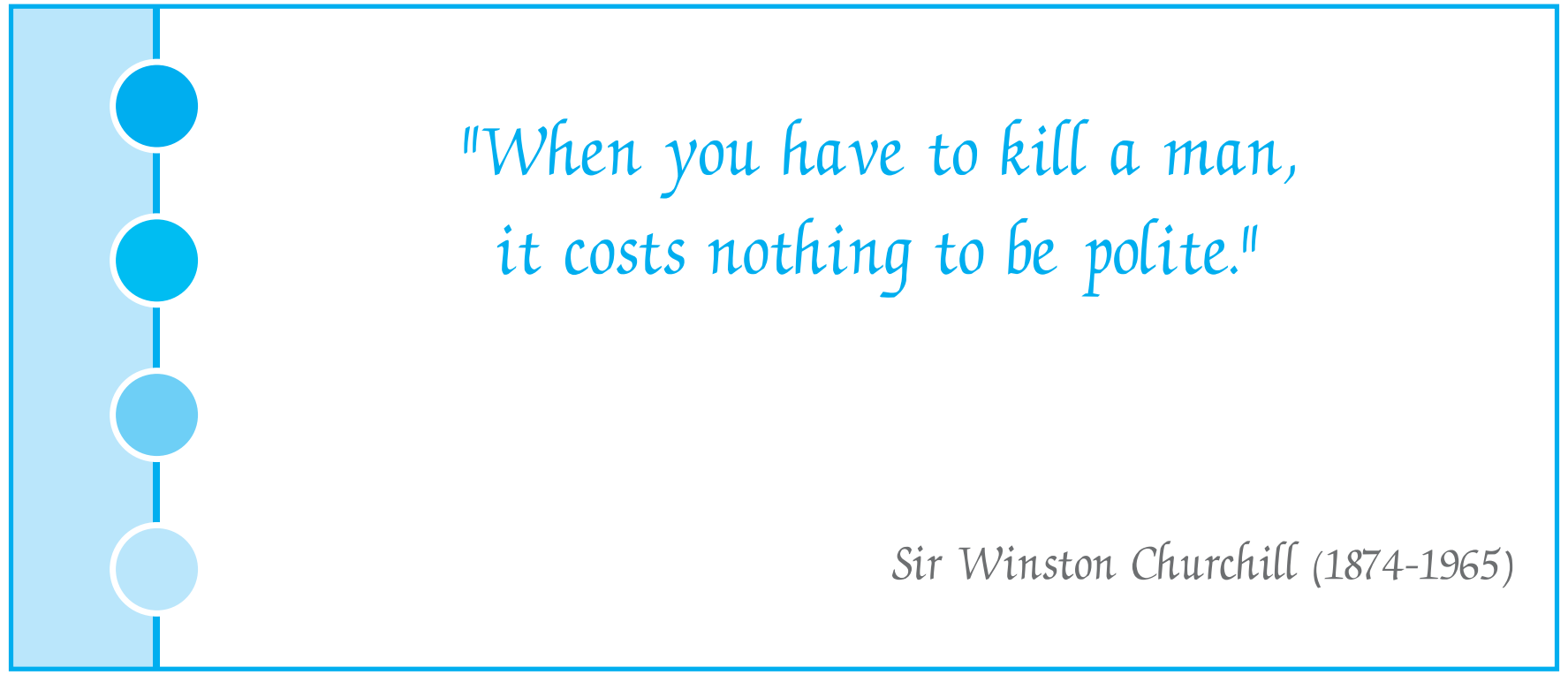

